\title{
Efficacy of single high-molecular-weight versus triple low-molecular-weight hyaluronic acid intra-articular injection among knee osteoarthritis patients
}

Mohammad Hasan Bahrami ${ }^{1}$, Seyed Ahmad Raeissadat ${ }^{2}$, Mohsen Cheraghi', Shahram Rahimi-Dehgolan ${ }^{3}$ and Adel Ebrahimpour ${ }^{4^{*}}$

\begin{abstract}
Background: To compare intra-articular (IA) knee injections of a cross-linked high-molecular-weight hyaluronic acid (HMW-HA) with a linear low-molecular weight HA (LMW-HA) in terms of pain and functional improvement among knee osteoarthritis (OA) patients.

Methods: In this single-blinded RCT, the patients were randomly divided into two groups for HA injections. The first group received an HMW-HA (Arthromac) injection, while the other received three weekly LMW-HA (Hyalgan) injections. Pain and function were assessed using the outcome measures including WOMAC, Lequesne and VAS indices, once prior to injection, as well as 2 and 6 months after injections.

Results: A total of 90 patients were included. There was no significant difference in baseline characteristics including age and sex between the two groups. Our analysis showed that total WOMAC, Lequesne and VAS mean scores remarkably improved at both follow-up time-points compared to the baseline measurements $(p<0.001)$. There was no significant superiority between the two therapeutic protocols according to our outcome measures at any time-point of follow-up. The only except was about the improvement in WOMAC stiffness subscale that was significantly higher in LMW-HA group compared to HMW-HA ( $p=0.021)$. Moreover, no significant difference was observed in minor complications and injection-induced pain scores between the two groups.

Conclusion: This study proved that a single HMW-HA injection is as effective as multiple injections of LMW-HA counterparts in periods of 2 and 6 months follow-up.

This study protocol was registered in Iranian database of RCTs (IRCT; www.irct.ir) with the trial registration number IRCT20130523013442N24 and registration date 2018-07-13.
\end{abstract}

Keywords: Intra-articular injections, Cross-linked, Hyaluronic acid, Knee osteoarthritis

\footnotetext{
* Correspondence: a.ebrahimpour@sbmu.ac.ir

${ }^{4}$ Orthopedic surgery Department, Taleghani Hospital, Shahid Beheshti

University of Medical Sciences, School of Medicine, No. 1998734383, Velenjak,

Tehran, Iran

Full list of author information is available at the end of the article
}

C The Author(s). 2020 Open Access This article is licensed under a Creative Commons Attribution 4.0 International License, which permits use, sharing, adaptation, distribution and reproduction in any medium or format, as long as you give appropriate credit to the original author(s) and the source, provide a link to the Creative Commons licence, and indicate if changes were made. The images or other third party material in this article are included in the article's Creative Commons licence, unless indicated otherwise in a credit line to the material. If material is not included in the article's Creative Commons licence and your intended use is not permitted by statutory regulation or exceeds the permitted use, you will need to obtain permission directly from the copyright holder. To view a copy of this licence, visit http://creativecommons.org/licenses/by/4.0/. The Creative Commons Public Domain Dedication waiver (http://creativecommons.org/publicdomain/zero/1.0/) applies to the data made available in this article, unless otherwise stated in a credit line to the data. 


\section{Background}

Osteoarthritis (OA) has been known to be the most common articular disease [1]. The prevalence of knee OA has doubled since the mid-twentieth century [2]. By examining the DALY among selected conditions throughout the world, knee and hip OA was determined to be at the 11th rank of global disability [3].

Treatments of knee are not considered to be a diseasemodifying therapy [4]. medications including nonsteroidal anti-inflammatory drugs (NSAIDs), acetaminophen, duloxetine, opioids, topical NSAIDs and capsaicin are effective in reducing symptoms [5]. Intra-articular injection, can be carried out using corticosteroid [6], hyaluronic acid (HA) [7], ozone [8], plasma rich in growth factor (PRGF) [9], and Platelet-rich plasma (PRP) [10]. Physical agent modalities have also been investigated regarding knee OA $[11,12]$. Many of international scientific associations have recommended Intra-articular hyaluronic acid (IA-HA) injections as part of knee OA treatment [13]. .HA has been compared with ozone [14], PRP [15], PRGF [16], and corticosteroid [17].

HA plays a role in traumatic energy dissipation and lubrication [18]. IA-HA is capable of decreasing nerve impulses related to $\mathrm{OA}$ pain. By benefiting from exogenous $\mathrm{HA}$, endogenous proteoglycan and hyaluronic acid production are improved [19]. HA binds to CD44 on chondrocytes and reduces IL-1 $\beta$ action that decrease activity of MMP-1, 2, 3, 9 and 13 [20]. HA also binds to hyaluronan mediated motility (RHAMM) receptor and could be helpful for chondroprotection [21]. Synovium nitricoxide production is also inhibited [22]. IA-HA is capable to reduce aggrecan degradation process [23]. IA-HA treatment can inhibit many inflammatory pathways through Toll-Like Receptors reducing TNF-a, IL-1 $\beta$, IL6, IL-17, MMP-13 and Nf-kB [24, 25]. IA-HA also affects the sub-chondral bone and its abnormal metabolism [26]. The concentration and molecular weight of IA$\mathrm{HA}$ in OA knee joints are lower than normal [27].

Differences exist in concentration, molecular weight, source of HA (biological fermentation-derived HA or avian-derived HA), dosage (number of injections and intervals), expected duration of effects, cross linkage and added formulations [28]. Based on HA molecular weight, these products are classified in three groups (high $\geq 3000 \mathrm{kDa}$, moderate $1500-3000 \mathrm{kDa}$ and low $\leq 1500$ $\mathrm{kDa}$ [29]. Many studies claim that high-molecularweight intra-articular hyaluronic acids (HMW IA-HA) have better chondro-protective, anti-inflammatory, proteoglycan production, rheologic, analgesic and mechanical properties [30]. They suggest that HMW IA-HA and those biological fermentation-derived HAs probably provide better efficacy and safety [29]. There are a widevariety of randomized clinical trials (RCTs) and systematic reviews with meta analyses concerning hyaluronic acid efficacy in knee OA [31, 32]; most of which reported beneficial effects in terms of pain and function. In a few studies the efficacy of single cross-linked HMW-HA has been investigated, though there exists a discrepancy between them [33-36]. Our utilized HMW-HA (Arthro$\operatorname{mac}^{\ominus}$, Novatex Bioengineering SA Switzerland) is one of these cross-linked products which is indicated for single intra-articular injection in knee OA patients [37].

The aim of current trial was to compare the efficacy and safety of the single cross-linked HMW injection versus triple injection of low-molecular-weight IA-HA among knee OA patients in terms of function and pain improvement during a six-month period.

\section{Methods}

\section{Participants}

In this RCT 90 patients aged between 45 and 75 years suffering from knee OA symptoms lasting for at least 3 months were included. Knee OA was classified according to Kellgren and Laurence score (KLS) [38]. Only subjects with KLS grade of II-III were eligible. The other exclusion criteria were as the followings: breastfeeding or pregnancy, vascular collagen and immunodeficiency disorders, diabetes mellitus, a history of malignancy, body mass index (BMI) $>32 \mathrm{~kg} / \mathrm{m}^{2}$, mal-alignment as genu varum or valgum greater than $20^{\circ}$, any knee trauma or intra-articular injection during the last 6 months, prior hypersensitivity reaction to avian products or egg protein.

This study protocol was also registered in Iranian database of RCTs (IRCT; www.irct.ir) with the trial registration number IRCT20130523013442N24 and registration date 2018-07-13. Besides, the Ethics Committee of Shahid Beheshti University of Medical Sciences was in charge of approving this study (No: IR.SBMU.MSP.REC.1396.899). A written informed consent was obtained; moreover, a physiatrist described the methodology, probable advantages and disadvantages of HA injections for every participant.

\section{Interventions}

The patients were randomly divided into two groups of 44 and 46 subjects using a computer software for random number generation. In the first group, a HMW-HA (Arthromac ${ }^{\bullet}$ Novatex Bioengineering SA Switzerland) was administered as a single intra-articular knee injection for 44 participants. HMW-HA solution was provided in a $3 \mathrm{~mL}$ prefilled syringe $(60 \mathrm{mg}$ of sodium hyaluronate). In the second group, 46 subjects received a low-molecular weight HA (molecular weight 500-730 kDa) (Hyalgan ${ }^{\oplus}$, Fidia Pharmaceutici S.P.A Italy) as three weekly sessions of IA injection. LMW-HA was provided in a $2 \mathrm{~mL}$ prefilled syringe ( $20 \mathrm{mg}$ of sodium hyaluronate). All injection were performed by an expert physiatrist who had 15 years of experience in intra articular 
injections. The physician who injected HAs was not blinded. Rather, the assessor physicians who were three senior residents remained unaware to patients' group till the end.

Our patients did not receive any anti-inflammatory or analgesic agents since 2 weeks before the first injection known as washout period. Prior to injection, routine skin cleansing with the aid of povidone-iodine was performed. Twenty-two gauge (22G) needles through lateral midpatellar approach for knee intra-articular injections were used to administer HMW-HA and LMW-HA in a sterile manner. Upon completion of injections, the participants were requested to flex and extend their knees 10 times. Next, the patients of both groups rested briefly, after which they were given a written protocol of exercises and recommendations to be performed at home. A period of 24-48 h rest along with 20-mintue cold therapy 3 times a day and restricted weight-bearing over knee joints were strongly suggested. The exercise therapy protocol comprised of isometric strengthening workouts that gradually progressed to closed-chain isotonic exercises. Hamstring stretching and muscles strengthening (quadriceps femoris, hip adductor groups, gluteus medius and maximus) were executed three times a day, each time lasting $15 \mathrm{~s}$ and repeating 5 times. All patients were followed-up for 8 and 24 weeks after the therapy using visual analog scale (VAS), Lequesne index, and Western Ontario and McMaster Universities Arthritis Index (WOMAC) questionnaire. VAS, WOMAC, and Lequesne indices were employed to investigate the patients' function and pain at three time-points; once at the baseline and two other times at the 2nd and 6th month after the injections [39-41]. Moreover, minor adverse events such as the injection-induced pain was assessed in both groups. For all indices, lower scores indicate a better condition.

\section{Statistical analysis}

Final data before and after the treatment were imported and analyzed in SPSS v.22. Normality of the data was evaluated using Shapiro-Wilk's test. Qualitative variables were expressed as frequency and percent. Chi square test was applied to analyze the differences of these qualitative parameters between the two groups. Also, the paired $t$-test and independent $t$-test were used to compare mean values within and between the two groups, respectively. In case of non-parametric data, we utilized Friedman and Mann-Whitney U tests, respectively. Statistical significance value was set at $P<0.05$.

\section{Results}

Among 158 patients with knee OA as candidates for IAHA injection, 68 patients were excluded from the study. Ninety subjects who met our criteria were randomized to the HMW-HA (44 patients) and LMW-HA (46 patients) groups and received IA-HA in a manner demonstrated in Fig. 1. Eleven participants discontinued the study; therefore, the final number of subjects for the analysis was 39 in the HMW-HA group and 40 in the LMW-HA group. There was no significant difference in baseline characteristics between the two groups (Table 1). The majority of

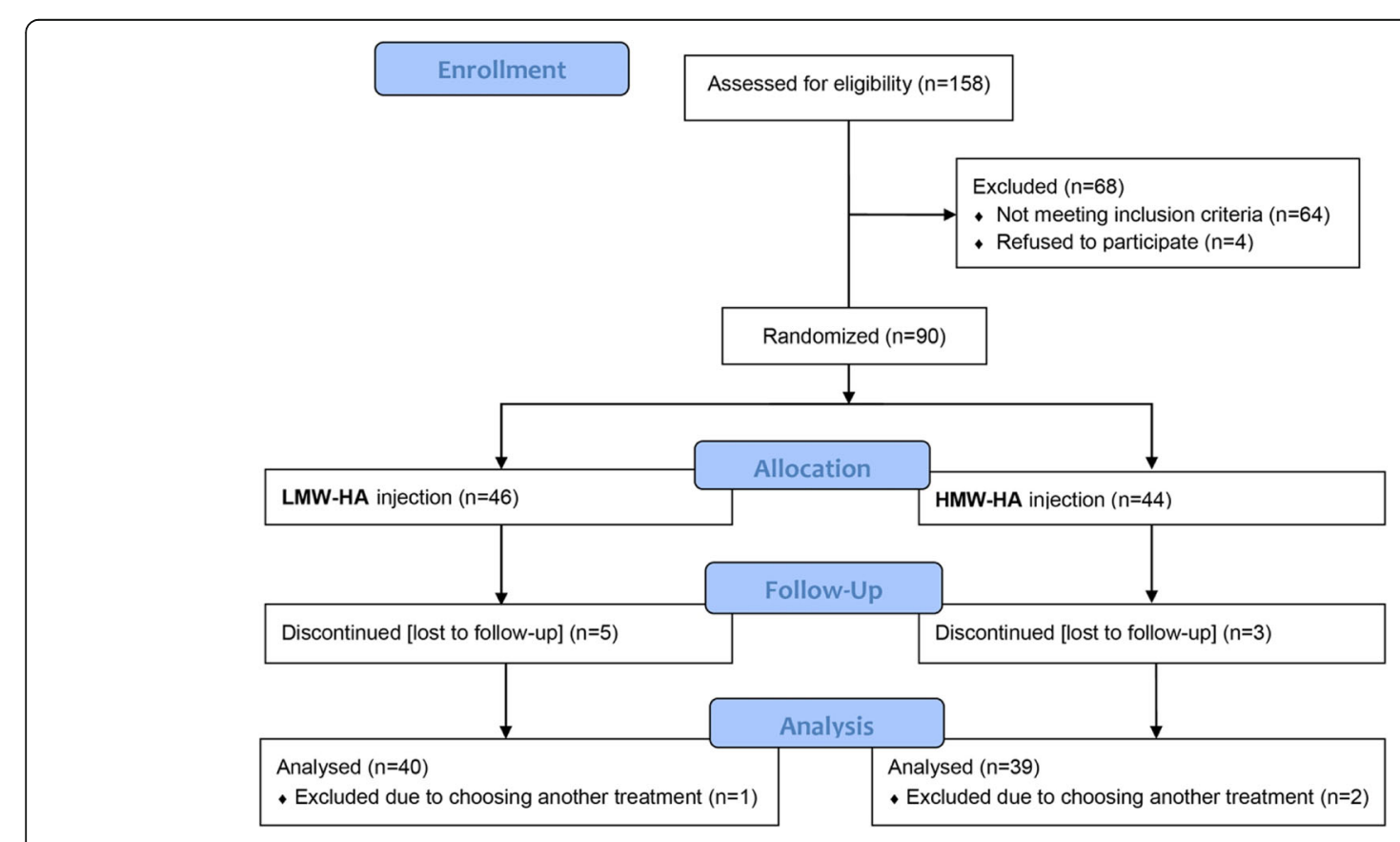

Fig. 1 Patient disposition 
Table 1 Baseline Demographic of the two groups

\begin{tabular}{llll}
\hline Variable & $\begin{array}{l}\mathrm{HMW} \\
(\boldsymbol{N}=39)\end{array}$ & $\begin{array}{l}\text { LMW-HA } \\
(\boldsymbol{N}=40)\end{array}$ & $\boldsymbol{P}$ value \\
\hline Age $_{\text {[year] Median (Range) }}$ & $56(41-66)$ & $59.5(45-70)$ & 0.305 \\
Weight $_{\text {[kg] Median (Range) }}$ & $74(59-98)$ & $75(57-89)$ & 0.879 \\
Height $_{\text {Mean (SD) }}$ & $1.66(0.09)$ & $1.65(0.07)$ & 0.521 \\
BMI $_{\text {[kg/m2] Median (Range) }}$ & $27.05(23-34)$ & $27.45(22-32)$ & 0.462 \\
Female: Male (\%) $_{\text {Right: Left (Number) }}$ & $71.8 \%: 28.2 \%$ & $75 \%: 25 \%$ & 0.747 \\
KLS Grade II: III (Number) & $20: 18$ & $16: 18$ & 0.21 \\
\hline
\end{tabular}

* The values are presented as the median, with the range in parentheses; Abbreviations: BMI Body Mass Index, KLS Kellgren Lawrence Score. " $P$ values refer to comparison between the two groups, based on the student's T-test

participants were female in both groups $(71.8 \%$ in HMWHA and 75\% in LMW-HA group).

Changes in WOMAC, Lequesne index and VAS mean values in each group have been demonstrated in Table 2. Findings showed that all outcome measuring tools statistically improved at 2 months and 6 months of follow-up, compared to the baseline level $(p<0.001)$. there was no significant difference between the LMW-HA and the HMW-HA groups based on three subscales of Lequesne index. Our analysis revealed a similar pattern in VAS mean values. In WOMAC subscale there was no superiority between two groups with one exception in WOMAC stiffness subscale at 2 months follow-up (Table 3). When comparing WOMAC stiffness improvement, LMW-HA was statistically superior to HMW-HA at the 2nd month follow-up $(P=0.021)$. Furthermore, success rates [defined as $\geq 30 \%$ decrease from baseline scores in WOMAC, Lequesne and VAS have been presented in Table 4.

Eventually, the frequency of minor complications and injection-induced pain have also been showed in Table 5 . Joint stiffness and swelling occurred in $8(20.5 \%)$ patients in the HMW-HA group versus 5 (12.5\%) subjects of the
Table 3 Comparison of efficacy between the two groups based on their clinical improvement

\begin{tabular}{llll}
\hline & HMW-HA & LMW-HA & $\boldsymbol{P}$ value \\
\hline Before [Mean] & & & \\
WOMAC & 42 & 44.00 & $\mathbf{0 . 7 1 3}^{\mathbf{a}}$ \\
Lequesne & 12.42 & 12.50 & $\mathbf{0 . 8 6 6 ^ { \mathbf { b } }}$ \\
VAS & 8 & 8.00 & $\mathbf{0 . 2 7 6}^{\mathbf{a}}$ \\
$\mathbf{2}$ months [Mean] & & & \\
WOMAC & 26.03 & 25.00 & $\mathbf{0 . 5 9 ^ { \mathbf { b } }}$ \\
Lequesne & 9.6 & 8.93 & $\mathbf{0 . 2 0 2 ^ { \mathbf { b } }}$ \\
VAS & 2 & 2.00 & $\mathbf{0 . 7 8 \mathbf { a } ^ { \mathbf { a } }}$ \\
$\mathbf{6}$ months [Mean] & & & \\
WOMAC & 24.08 & 26.55 & $\mathbf{0 . 2 4 7 ^ { \mathbf { b } }}$ \\
Lequesne & 8.97 & 9.73 & $\mathbf{0 . 1 2 6 ^ { \mathbf { b } }}$ \\
VAS & 3 & 4.00 & $\mathbf{0 . 4 1 1 ^ { \mathbf { a } }}$ \\
\hline
\end{tabular}

a values refer to comparison between the two groups, based on the Mann-Whitney test

${ }^{b} P$ values refer to comparison between the two groups, based on the student's T-test

LMW-HA group $(P=0.378)$. The mean value of injection-induced pain was 2.64 and 1.9 in HMW-HA and LMW-HA groups, respectively $(P=0.286)$. Fortunately, no systemic adverse event or major complication such as septic arthritis was reported in the present RCT.

\section{Discussion}

Based on results of this study clinical improvement with a single cross-linked HMW-HA injection could be relatively equal to that of triple injection of a linear LMWHA, within the periods of two and 6 months follow-up. Moreover, a comparison between the two groups indicates that there exists no statistically significant superiority. An exception was the improvement of WOMAC

Table 2 Comparison of efficacy within the two groups based on changes from the baseline

\begin{tabular}{|c|c|c|c|c|c|c|c|c|c|}
\hline & \multicolumn{4}{|l|}{ WOMAC } & \multicolumn{4}{|c|}{ Lequesne } & \multirow{2}{*}{$\begin{array}{l}\text { VAS } \\
\text { VAS }\end{array}$} \\
\hline & pain & stiffness & Function & Total & pain & walk & $\mathrm{ADL}$ & Total & \\
\hline \multicolumn{10}{|c|}{ HMW-HA [Mean] } \\
\hline Before & 9 & 3 & 30 & 42 & 5 & 2 & 5.5 & 12.5 & 8 \\
\hline 2 months & 5 & 2 & 19 & 25 & 4 & 1 & 4.5 & 10 & 2 \\
\hline 6 months & 5 & 1 & 17 & 22 & 3 & 1 & 4 & 8.5 & 3 \\
\hline${ }^{*} P$ value & $<0.001$ & $<0.001$ & $<0.001$ & $<0.001$ & $<0.001$ & $<0.001$ & $<0.001$ & $<0.001$ & $<0.001$ \\
\hline \multicolumn{10}{|c|}{ LMW-HA [Mean] } \\
\hline Before & 9 & 3 & 30 & 44 & 5.5 & 1 & 5.5 & 12.5 & 8 \\
\hline 2 months & 5 & 1 & 18 & 25 & 3 & 1 & 4 & 9 & 2 \\
\hline 6 months & 5 & 1 & 17 & 24.5 & 3.5 & 1 & 4.5 & 9.75 & 4 \\
\hline${ }^{*} P$ value & $<0.001$ & $<0.001$ & $<0.001$ & $<0.001$ & $<0.001$ & $<0.001$ & $<0.001$ & $<0.001^{\#}$ & $<0.001$ \\
\hline
\end{tabular}

* $P$ values refer to changes over time within each group, based on the Friedman test

$\# P$ values refer to changes over time within each treatment group, based on Repeated Measures 
Table 4 Clinical improvement as percent of changes in mean outcome scores over the time-points

\begin{tabular}{|c|c|c|c|c|c|c|c|c|c|}
\hline & \multicolumn{4}{|c|}{ WOMAC (points) } & \multicolumn{4}{|l|}{ LEQUESNE } & \multirow{2}{*}{$\begin{array}{l}\text { VAS } \\
\text { VAS }\end{array}$} \\
\hline & pain & stiffness & Function & Total & Pain & walk & ADL & Total & \\
\hline \multicolumn{10}{|l|}{ HMW-HA } \\
\hline Before & $9.74(0.22)$ & $2.72(0.19)$ & $29.92(1.04)$ & $42.38(1.24)$ & $5.08(0.16)$ & $1.67(0.09)$ & $5.68(0.11)$ & $12.42(0.26)$ & $7.82(0.18)$ \\
\hline 2 months & $5.00(0.27)$ & $2.65(0.17)$ & $19.46(1.12)$ & $26.03(1.4)$ & $3.95(0.19)$ & $1.21(0.09)$ & $4.45(0.19)$ & $9.60(0.40)$ & $2.69(0.22)$ \\
\hline 6 months & $5.05(0.28)$ & $1.41(0.19)$ & $17.62(1.18)$ & $24.08(1.55)$ & $3.49(0.22)$ & $1.38(0.11)$ & $4.10(0.19)$ & $8.97(0.44)$ & $3.46(0.17)$ \\
\hline Mean Difference ${ }^{\mathrm{a}}(\mathrm{SD})$ & $-4.7(0.32)$ & $-1.3(0.26)$ & $-12.30(0.9)$ & $-18.30(1.23)$ & $-1.6(0.23)$ & $-0.28(0.1)$ & $-1.57(0.2)$ & $-3.45(0.38)$ & $-4.36(0.27)$ \\
\hline $\begin{array}{l}\text { Change }^{\mathrm{b}}(\%) \text { from } \\
\text { baseline [SD] }\end{array}$ & $47.77[2.96]$ & $58.16[5.56]$ & $41.82[3.17]$ & $43.76[3.06]$ & $37.38[3.63]$ & $29.91[5.94]$ & $28.29[3.23]$ & $29.93[2.77]$ & $55.17[3.20]$ \\
\hline $\begin{array}{l}\text { Success Rate }{ }^{c} \text { (Number) } \\
{[\%]}\end{array}$ & 31 [79.5] & $30[83.3]$ & $28[71.8]$ & $25[64.1]$ & $24[61.5]$ & 18 [46.2] & $13[33.3]$ & $18[46.2]$ & $34[87.2]$ \\
\hline${ }^{*} P$ value & $<0.001$ & $<0.001$ & $<0.001$ & $<0.001$ & $<0.001$ & $<0.001$ & $<0.001$ & $<0.001$ & $<0.001$ \\
\hline \multicolumn{10}{|l|}{ LMW-HA } \\
\hline Before & $9.28(0.26)$ & $2.65(0.19)$ & $29.88(1.24)$ & $41.33(1.65 \mathrm{~V})$ & $5.53(0.15)$ & $1.58(0.13)$ & $5.63(0.12)$ & $12.50(0.36)$ & $8.15(0.17)$ \\
\hline 2 months & $4.83(0.23)$ & $1.05(0.16)$ & $18.40(1.01)$ & $25.00(1.33)$ & $3.50(0.17)$ & $1.15(0.10)$ & $4.18(0.15)$ & $8.93(0.34)$ & $2.65(0.18)$ \\
\hline 6 months & $5.30(0.24)$ & $1.00(0.14)$ & $19.00(1.05)$ & $26.55(1.43)$ & $3.75(0.19)$ & $1.28(0.11)$ & $4.65(0.16)$ & $9.93(0.42)$ & $3.65(0.18)$ \\
\hline Mean Difference ${ }^{a}(S D)$ & $-3.97(0.25)$ & $-1.65(0.14)$ & $-10.87(1.07)$ & $-14.77(1.05)$ & $-1.77(0.19)$ & $-0.30(0.11)$ & $-0.975(0.13)$ & $-2.57(0.28)$ & $-4.50(0.25)$ \\
\hline $\begin{array}{l}\text { Change }^{\mathrm{b}}(\%) \text { from } \\
\text { baseline [SD] }\end{array}$ & $42.56[2.26]$ & $63.20[4.72]$ & $36.55[2.52]$ & $35.62[2.33]$ & $32.62[2.98]$ & $17.98[5.12]$ & $19.03[2.23]$ & $21.21[2.20]$ & $54.71[2.67]$ \\
\hline $\begin{array}{l}\text { Success Rate }{ }^{c} \text { (Number) } \\
{[\%]}\end{array}$ & 34 [85] & $34[87.2]$ & $27[67.5]$ & $29[72.5]$ & $21[52.5]$ & $11[28.9]$ & $7[17.5]$ & 9 [22.5] & 36 [90] \\
\hline${ }^{*} P$ value & $<0.001$ & $<0.001$ & $<0.001$ & $<0.001$ & $<0.001$ & $<0.001$ & $<0.001$ & $<0.001^{\#}$ & $<0.001$ \\
\hline${ }^{* * P}$ value & 0.66 & 0.21 & 0.94 & 0.94 & 0.69 & 0.53 & 0.70 & 0.80 & 0.48 \\
\hline
\end{tabular}

${ }^{*} P$ values refer to changes over time within each group, based on the Repeated Measures; ${ }^{* *} p$ value between groups, based on the Repeated Measures; ${ }^{\text {a }}$ (6th month-Baseline); ${ }^{b}$ ([6th month-Baseline]/Baseline) ${ }^{*} 100 ;{ }^{c}$ for each participant $30 \%$ change was considered as the success

stiffness subscale which was significantly higher in LMW-HA group in 2 months.

Altman [29] review which included 68 randomized trials proved that HMW-HA efficacy was superior to LMW-HAs. Conversely in our study, there was no difference in efficacy between these two types of HAs. In the study conducted by Zhang et al. [36], the therapeutic effectiveness of single injection of a cross-linked HMWHA (Durolane) was compared to five injections of a LMW-HA (Artz), showing that during a period of 26

Table 5 Comparison of adverse-events occurrence between the two groups

\begin{tabular}{llll}
\hline & HMW-HA & LMW-HA & $p$-value \\
\hline $\begin{array}{l}\text { Post injection pain } \\
\text { Mean (SD) }\end{array}$ & $2.64(2.265)$ & $1.90(1.392)$ & $0.286^{\mathrm{a}}$ \\
$\begin{array}{l}\text { Stiffness and heaviness } \\
\text { Number (Frequency \%) }\end{array}$ & $4(10.26 \%)$ & $3(7.5 \%)$ & $0.712^{\mathrm{b}}$ \\
$\begin{array}{l}\text { Swelling } \\
\text { Number (Frequency \%) }\end{array}$ & $4(10.26 \%)$ & $2(5 \%)$ & $0.432^{\mathrm{b}}$ \\
$\begin{array}{l}\text { Total } \\
\text { Number (Frequency \%) }\end{array}$ & $8(20.51 \%)$ & $5(12.5 \%)$ & $0.378^{\mathrm{b}}$ \\
$\begin{array}{l}\text { a } P \text { values refer to comparison between the two groups, based on the } \\
\text { student's T-test } \\
{ }_{\mathrm{b} P} P \text { values refer to comparison between the two groups, based on Chi } \\
\text { square test }\end{array}$
\end{tabular}

weeks, Durolane was non-inferior to Artz in terms of pain, physical activity and knee-stiffness. Our study revealed a similar result within a period of same length.

Similarly, Diracoglu et al. [33] evaluated the efficacy of two HA types with different molecular weights and number of injections. The first group received a single cross-linked moderate-molecular-weight HA (Monovisc), while the other one underwent three consecutive weekly injections of a linear LMW-HA (Adant). In both groups, WOMAC scores and VAS-pain showed statistically significant improvements compared to the baseline level, without any remarkable superiority between the two groups. However, in both groups, WOMAC stiffness showed no significant improvement. Meanwhile, VAS improvement for the group receiving Adant was remarkably higher than the Monovisc group. The latter study found that a single cross-linked HA can be as effective as a triple linear LMW-HA, exactly similar to our study. It should be pointed out that the HA used in our trial was much heavier than the one used by Diracoglu. Unlike the mentioned results, WOMAC stiffness in our investigation was associated with a statistically significant improvement. This change was even more evident in the group receiving LMW-HA compared to HMW-HA group. 
Another study by Estades-Rubio et al. [35], evaluated a single dose of Durolane versus a five-time $\mathrm{GO} \mathrm{ON}^{\circledR}$ injection. Mobility and WOMAC were assessed during 6 months. A statistically significant change was observed for both groups compared to their baseline level. In addition, a remarkable superiority was observed in WOMAC scores of the group receiving Durolane compared to the $\mathrm{GO} \mathrm{ON}^{\circ}$ group, although no difference was detected in mobility values. From the economic point of view, the total price of using a single injection of Durolane was lower than that of multiple injections of $\mathrm{GO}$ $\mathrm{ON}^{\circ}$. In comparison, the results of our RCT showed some dissimilarities since the improvement in the Durolane as a cross-linked HMW-HA is statistically more significant than $\mathrm{GO} \mathrm{ON}^{\bullet}$. However, this finding proves that a single cross-linked HMW-HA can be as effective as or even better than multiple linear LMW-HA injections.

In the meta-analysis conducted by Concoff et al. [34], the efficacy of multiple HA injections versus a single dose of HA was studied. The pooled data showed that a single HA injection was not significantly more effective than IA-Saline in a period of 6 months. Another systematic review and meta-analysis by Zhao et al. [42], was carried out to compare the results of Hylan G-F 20 and LMW-HA in knee OA patients. The final results indicate a similarity between the Hylan G-F 20 and LMWHA groups in terms of their pain-relief effect. However, Hylan G-F 20 was more effective in pain improvement from 2 to 3 months. It should be pointed out that in the present meta-analysis, Hylan G-F 20 injections were administered more than once; however, this number was less than the number of LMW-HA injections in most trials. These findings, similar to our study, showed the effectiveness of HMW-HA with lower number of injections compared to LMW-HA with multiple injections.

In our study, the rate of minor complications and injection-induced pain was not statistically different between two HA products. In Bannuru's meta-analysis [43], none of the HA products were significantly different from each other with regard to incidence of adverse events and were relatively equal to IA placebo. Altman et al. [29], concluded that there is no significant difference in the occurrence of effusion across molecular weight subgroups. Different brand names of HA exist in the market, claiming to be effective by a single injection. So far, few studies have been conducted to compare a single HA injection with multiple HA injection. Although most single-injection HAs are of HMW and cross-linked type, some differences can be observed in their structure. To examine the exact effects of such viscosupplements, further well-designed investigations should be performed. Evidently, single injections possess the advantage of lower cost, patients' comfort and lower risk of complications owing to the lower number of injections.

An advantage of this research is employing various outcome measures for evaluating patients' symptoms including WOMAC subscales, Lequesne and VAS indices. The washout period was considered in this study. The fact that the physician was not blind in this study, is an important limitation. Due to ethical issues, it was not possible to do second and third sham injections in HMW-HA group. Rather, all assessors in this study were completely blinded. It would be better to enroll a higher number of patients in the future studies. Although our follow-up was for 6 months, yet longer follow-up time can be suggested. As the last limitation to be mentioned, no economic analysis was conducted in our trial.

\section{Conclusion}

Both HMW IA-HA and LMW IA-HA caused significant functional improvement and pain relief; however, there was no significant difference between HMW IA-HA versus three weekly LMW IA-HA in terms of pain relief and function improvement in knee osteoarthritis patients in 6 months of follow-ups. This study revealed that a single HMW-HA injection is as effective as multiple injections of LMW-HA counterparts in periods of 2 and 6 months. Further research into the subject probably sheds lights on choosing the more suited protocol of HA injections.

\section{Supplementary information}

Supplementary information accompanies this paper at https://doi.org/10. 1186/s12891-020-03577-8

Additional file 1. CONSORT 2010 checklist.

\section{Abbreviations}

HMW-HA: High-molecular-weight hyaluronic acid; LMW-HA: Low-molecularweight hyaluronic acid; OA: Osteoarthritis; NSAIDs: Nonsteroidal antiinflammatory drugs; PRGF: Plasma rich in growth factor; PRP: Platelet-rich plasma; IA-HA: Intra-articular hyaluronic acid; RCTs: Randomized clinical trials; MMPs: Matrix metalloproteinases; KLS: Kellgren and Lawrence score; BMI: Body mass index; VAS: Visual analog scale; WOMAC: Western Ontario and McMaster Universities Arthritis Index

\section{Acknowledgements}

This article has been extracted from the thesis written by Dr. Mohsen Cheraghi in School of Medicine, Shahid Beheshti University of Medical Sciences. The authors would like to appreciate the help of Mrs. Mehrnaz Mehrabi in Shahid Modarres Clinical Research Development Center.

\section{CONSORT guidelines}

Our study adheres to CONSORT guidelines and a completed CONSORT checklist is added in an additional file.

\section{Authors' contributions}

SAR and MC designed the clinical trial. Data analysis was done by SAR, SRD and MC. MC prepared the first draft of the article. AE and MHB took care of its revisions. All the authors contributed to interpretation of the results and preparation of the article. All authors approved the final version of the article to be published. 


\section{Funding}

This RCT had no external funding source.

\section{Availability of data and materials}

The authors do not intend to share substantial data of this study; but they are ready to share the de-identified file of substantial data in excel format and all other study-related documents, at any specific time for any period, on the demand of editorial board via the corresponding author's email.

\section{Ethics approval and consent to participate}

This study protocol was also registered in Iranian database of RCTs (IRCT; www.irct.ir) with ID number of 31564. Besides, the Ethics Committee of Shahid Beheshti University of Medical Sciences was in charge of approving this study (No: IR.SBMU.MSP.REC.1396.899). A written informed consent was obtained; moreover, a physiatrist described the methodology, probable advantages and disadvantages of HA injections for every participant.

\section{Consent for publication}

Not Applicable.

\section{Competing interests}

The authors declare that they have no financial or non-financial competing interests.

\section{Author details}

'Physical Medicine and Rehabilitation Department and Research Center, Shohada-e-Tajrish Hospital, Shahid Beheshti University of Medical Sciences, School of Medicine, Tehran, Iran. ${ }^{2}$ Clinical Development Research Center of Shahid Modarres Hospital, Physical Medicine and Rehabilitation Department and Research Center, Shahid Beheshti University of Medical Sciences, School of Medicine, Tehran, Iran. ${ }^{3}$ Physical Medicine and Rehabilitation Department, Tehran University of Medical Sciences (TUMS), School of Medicine, Tehran, Iran. ${ }^{4}$ Orthopedic surgery Department, Taleghani Hospital, Shahid Beheshti University of Medical Sciences, School of Medicine, No. 1998734383, Velenjak, Tehran, Iran

\section{Received: 27 September 2019 Accepted: 6 August 2020}

\section{Published online: 15 August 2020}

\section{References}

1. Vos T, Flaxman AD, Naghavi M, Lozano R, Michaud C, Ezzati M, Shibuya K, Salomon JA, Abdalla S, Aboyans V, et al. Years lived with disability (YLDs) for 1160 sequelae of 289 diseases and injuries 1990-2010: a systematic analysis for the global burden of disease study 2010. Lancet. 2012;380(9859):216396.

2. Wallace I, Worthington S, Felson D, Jurmain R, Wren $\mathrm{K}$, Maijanen $\mathrm{H}$, Woods $\mathrm{R}$, Lieberman D. Knee osteoarthritis has doubled in prevalence since the mid-20th century. Proc Natl Acad Sci. 2017:114:201703856.

3. Cross M, Smith E, Hoy D, et al. The global burden of hip and knee osteoarthritis: estimates from the global burden of disease 2010 study. Ann Rheum Dis. 2014;73(7):1323-30. https://doi.org/10.1136/annrheumdis-2013204763.

4. Bannuru RR, Vaysbrot EE, Sullivan MC, McAlindon TE. Relative efficacy of hyaluronic acid in comparison with NSAIDs for knee osteoarthritis: a systematic review and meta-analysis. Seminars in Arthritis and Rheumatism. 2014;43(5):593-9. https://doi.org/10.1016/j.semarthrit.2013.10.002.

5. McAlindon TE, Bannuru RR, Sullivan M, Arden N, Berenbaum F, BiermaZeinstra S, Hawker G, Henrotin Y, Hunter D, Kawaguchi H. OARSI guidelines for the non-surgical management of knee osteoarthritis. Osteoarthr Cartil. 2014;22(3):363-88

6. da Costa BR, Hari R, Juni P. Intra-articular corticosteroids for osteoarthritis of the knee. JAMA. 2016;316(24):2671-2.

7. He WW, Kuang MJ, Zhao J, Sun L, Lu B, Wang Y, Ma JX, Ma XL. Efficacy and safety of intraarticular hyaluronic acid and corticosteroid for knee osteoarthritis: a meta-analysis. Int J Surg. 2017;39:95-103.

8. Raeissadat SA, Tabibian E, Rayegani SM, Rahimi-Dehgolan S, Babaei-Ghazani A. An investigation into the efficacy of intra-articular ozone (O2-O3) injection in patients with knee osteoarthritis: a systematic review and metaanalysis. J Pain Res. 2018;11:2537.

9. Sánchez M, Fiz N, Azofra J, Usabiaga J, Recalde EA, Gutierrez AG, Albillos J, Gárate R, Aguirre JJ, Padilla S. A randomized clinical trial evaluating plasma rich in growth factors (PRGF-Endoret) versus hyaluronic acid in the shortterm treatment of symptomatic knee osteoarthritis. Arthrosc J Arthrosc Relat Surg. 2012;28(8):1070-8.

10. Ayhan E, Kesmezacar H, Akgun I. Intraarticular injections (corticosteroid, hyaluronic acid, platelet rich plasma) for the knee osteoarthritis. World J Orthop. 2014:5(3):351-61.

11. Nouri F, Raeissadat SA, Eliaspour D, Rayegani SM, Rahimi MS, Movahedi B. Efficacy of high-power laser in alleviating pain and improving function of patients with patellofemoral pain syndrome: a single-blind randomized Controlled trial. J Lasers Med Sci. 2019;10(1):37-43.

12. Raeissadat SA, Rayegani SM, Sedighipour L, Bossaghzade Z, Abdollahzadeh $\mathrm{MH}$, Nikray R, Mollayi F. The efficacy of electromyographic biofeedback on pain, function, and maximal thickness of vastus medialis oblique muscle in patients with knee osteoarthritis: a randomized clinical trial. J Pain Res. 2018; 11:2781-9.

13. Cooper $C$, Rannou F, Richette $P$, Bruyère $O$, Al-Daghri N, Altman RD, Brandi ML, Collaud Basset S, Herrero-Beaumont G, Migliore A. Use of intraarticular hyaluronic acid in the management of knee osteoarthritis in clinical practice. Arthritis Care Res. 2017;69(9):1287-96.

14. Raeissadat SA, Rayegani SM, Forogh B, Abadi PH, Moridnia M, Dehgolan SR. Intra-articular ozone or hyaluronic acid injection: which one is superior in patients with knee osteoarthritis? A 6-month randomized clinical trial. J Pain Res. 2018;11:111.

15. Raeissadat SA, Rayegani SM, Hassanabadi H, Fathi M, Ghorbani E, Babaee M, Azma K. Knee osteoarthritis injection choices: platelet-rich plasma (PRP) versus hyaluronic acid (a one-year randomized clinical trial). Clin Med Insight. 2015;8:CMAMD. S17894.

16. Raeissadat SA, Rayegani SM, Ahangar AG, Abadi PH, Mojgani P, Ahangar OG Efficacy of intra-articular injection of a newly developed plasma rich in growth factor (PRGF) versus hyaluronic acid on pain and function of patients with knee osteoarthritis: a single-blinded randomized clinical trial. Clin Med Insight. 2017;10:1179544117733452.

17. Stahl S, Karsh-Zafrir I, Ratzon N, Rosenberg N. Comparison of intraarticular injection of depot corticosteroid and hyaluronic acid for treatment of degenerative trapeziometacarpal joints. JCR J Clin Rheumatol. 2005;11(6):299-302

18. Tascioglu F, Öner C. Efficacy of intra-articular sodium hyaluronate in the treatment of knee osteoarthritis. Clin Rheumatol. 2003;22(2):112-7.

19. Moreland LW. Intra-articular hyaluronan (hyaluronic acid) and hylans for the treatment of osteoarthritis: mechanisms of action. Arthritis Res Ther. 2003; 5(2):54.

20. Julovi SM, Yasuda T, Shimizu M, Hiramitsu T, Nakamura T. Inhibition of interleukin-1 $\beta$-stimulated production of matrix metalloproteinases by hyaluronan via CD44 in human articular cartilage. Arthritis Rheum. 2004 50(2):516-25.

21. Karna E, Miltyk W, Surażyński A, Pałka JA. Protective effect of hyaluronic acid on interleukin-1-induced deregulation of $\beta$ 1-integrin and insulin-like growth factor-I receptor signaling and collagen biosynthesis in cultured human chondrocytes. Mol Cell Biochem. 2008;308(1-2):57-64

22. Peng H, Zhou J-L, Liu S-Q, Hu Q-J, Ming J-H, Qiu B. Hyaluronic acid inhibits nitric oxide-induced apoptosis and dedifferentiation of articular chondrocytes in vitro. Inflamm Res. 2010:59(7):519-30.

23. Yatabe T, Mochizuki S, Takizawa M, Chijiiwa M, Okada A, Kimura T, Fujita Y, Matsumoto H, Toyama Y, Okada Y. Hyaluronan inhibits expression of ADAM TS4 (aggrecanase-1) in human osteoarthritic chondrocytes. Ann Rheum Dis. 2009;68(6):1051-8.

24. Campo GM, Avenoso A, D'Ascola A, Scuruchi M, Prestipino V, Nastasi G, Calatroni A, Campo S. The inhibition of hyaluronan degradation reduced pro-inflammatory cytokines in mouse synovial fibroblasts subjected to collagen-induced arthritis. J Cell Biochem. 2012;113(6):1852-67.

25. Campo G, Avenoso A, Nastasi G, Micali A, Prestipino V, Vaccaro M, D'Ascola A, Calatroni A, Campo S. Hyaluronan reduces inflammation in experimental arthritis by modulating TLR-2 and TLR-4 cartilage expression. Biochim Biophys Acta. 2011;1812:1170-81

26. Hiraoka N, Takahashi KA, Arai Y, Sakao K, Mazda O, Kishida T, Honjo K, Tanaka S, Kubo T. Intra-articular injection of hyaluronan restores the aberrant expression of matrix metalloproteinase-13 in osteoarthritic subchondral bone. J Orthop Res. 2011;29(3):354-60.

27. Dahl L, Dahl I, Engström-Laurent A, Granath K. Concentration and molecular weight of sodium hyaluronate in synovial fluid from patients with rheumatoid arthritis and other arthropathies. Ann Rheum Dis. 1985:44(12): 817-22. 
28. Migliore A, Bizzi E, De Lucia O, Sedie AD, Bentivegna M, Mahmoud A, Foti C. Differences among branded hyaluronic acids in italy, part 1: data from in vitro and animal studies and instructions for use. Clin Med Insight. 2016;9: CMAMD. S38857.

29. Altman RD, Bedi A, Karlsson J, Sancheti P, Schemitsch E. Product Differences in Intra-articular Hyaluronic Acids for Osteoarthritis of the Knee. Am J Sports Med. 2016;44(8):2158-65. https://doi.org/10.1177/0363546515609599.

30. Altman RD, Manjoo A, Fierlinger A, Niazi F, Nicholls M. The mechanism of action for hyaluronic acid treatment in the osteoarthritic knee: a systematic review. BMC Musculoskelet Disord. 2015;16(1):321.

31. Bellamy N, Campbell J, Welch V, Gee TL, Bourne R, Wells GA. Viscosupplementation for the treatment of osteoarthritis of the knee. Cochrane Libr. 2006.

32. Chen-Ti W, Lin J, Chee-Jen C, Yu-Tsan L, Hou S-M. Therapeutic effects of hyaluronic acid on osteoarthritis of the knee: a META-analysis of randomized CONTROLLED trials. J Bone Joint Surg. 2004;86(3):538.

33. Dıraçoğlu D, Tunçay TB, Şahbaz T, Aksoy C. Single versus multiple dose hyaluronic acid: comparison of the results. J Back Musculoskelet Rehabil. 2016;29(4):881-6.

34. Concoff A, Sancheti P, Niazi F, Shaw P, Rosen J. The efficacy of multiple versus single hyaluronic acid injections: a systematic review and metaanalysis. BMC Musculoskelet Disord. 2017;18(1):542.

35. Estades-Rubio FJ, Reyes-Martín A, Morales-Marcos V, García-Piriz M, GarcíaVera JJ, Perán M, Marchal JA, Montañez-Heredia E. Knee Viscosupplementation: cost-effectiveness analysis between stabilized hyaluronic acid in a single injection versus five injections of standard hyaluronic acid. Int J Mol Sci. 2017;18(3).

36. Zhang H, Zhang K, Zhang X, Zhu Z, Yan S, Sun T, Guo A, Jones J, Steen RG, Shan B, et al. Comparison of two hyaluronic acid formulations for safety and efficacy (CHASE) study in knee osteoarthritis: a multicenter, randomized, double-blind, 26-week non-inferiority trial comparing Durolane to Artz. Arthritis Res Ther. 2015;17(1):51.

37. What is ARTHROMAC [http://www.arthromac.com/en/osteoarthritistreatment.html].

38. Kellgren J, Lawrence J. Radiological assessment of osteo-arthrosis. Ann Rheum Dis. 1957;16(4):494.

39. Bellamy N, Buchanan WW, Goldsmith CH, Campbell J, Stitt LW. Validation study of WOMAC: a health status instrument for measuring clinically important patient relevant outcomes to antirheumatic drug therapy in patients with osteoarthritis of the hip or knee. J Rheumatol. 1988;15(12): 1833-40.

40. Carlsson AM. Assessment of chronic pain. I. Aspects of the reliability and validity of the visual analogue scale. Pain. 1983;16(1):87-101.

41. Faucher M, Poiraudeau S, Lefevre-Colau MM, Rannou F, Fermanian J, Revel M. Assessment of the test-retest reliability and construct validity of a modified Lequesne index in knee osteoarthritis. Joint Bone Spine. 2003; 70(6):521-5

42. Zhao H, Liu H, Liang X, Li Y, Wang J, Liu C. Hylan GF 20 versus low molecular weight hyaluronic acids for knee osteoarthritis: a meta-analysis. BioDrugs. 2016;30(5):387-96.

43. Bannuru RR, Osani M, Vaysbrot EE, McAlindon TE. Comparative safety profile of hyaluronic acid products for knee osteoarthritis: a systematic review and network meta-analysis. Osteoarthr Cartil. 2016;24(12):2022-41.

\section{Publisher's Note}

Springer Nature remains neutral with regard to jurisdictional claims in published maps and institutional affiliations.

Ready to submit your research? Choose BMC and benefit from:
- fast, convenient online submission
- thorough peer review by experienced researchers in your field
- rapid publication on acceptance
- support for research data, including large and complex data types
- gold Open Access which fosters wider collaboration and increased citations
- maximum visibility for your research: over 100M website views per year
At BMC, research is always in progress.
Learn more biomedcentral.com/submissions

